\title{
How Does Liquidity Affect Government Bond Yields?*
}

\author{
Carlo Favero $^{\dagger} \quad$ Marco Pagano ${ }^{\ddagger} \quad$ Ernst-Ludwig von Thadden ${ }^{\S}$
}

May 2008

\begin{abstract}
The paper explores the determinants of yield differentials between sovereign bonds, using Euro area data. There is a common trend in yield differentials, which is correlated with a measure of aggregate risk. In contrast, liquidity differentials display sizeable heterogeneity and no common factor. We propose a simple model with endogenous liquidity demand, where a bond's liquidity premium depends both on its transaction cost and on investment opportunities. The model predicts that yield differentials should increase in both liquidity and risk, with an interaction term of the opposite sign. Testing these predictions on daily data, we find that the aggregate risk factor is consistently priced, liquidity differentials are priced for a subset of countries, and their interaction with the risk factor is in line with the model's prediction and crucial to detect their effect.
\end{abstract}

JEL classification numbers: E43, G12.

${ }^{*}$ We gratefully acknowledge comments by an anonymous referee, Stefan Gerlach, Eugene Kandel, Philippe Martin, Henri Pages, Eli Remolona, Raman Uppal and seminar participants at Bocconi University, the Banque de France, CEMFI (Madrid), the Bundebank and the ECB-CFS Research Network on "Capital Markets and Financial Integration in Europe". We are grateful to the Fondation Banque de France for providing most of the funding for this project, and to Inquire for additional financial support. Euro MTS, and in particular its former CEO Gianluca Garbi, kindly supplied data and useful comments. Stephan Maier and Michele Galietta provided able research assistance.

${ }^{\dagger}$ Università Bocconi, IGIER and CEPR. Contact information: IGIER, Università Commerciale Luigi Bocconi, Via Salasco 5, 20136 Milan, Italy, ph. +39-02-58363306, e-mail carlo.favero@uni-bocconi.it.

${ }^{\ddagger}$ Università di Napoli Federico II, CSEF, EIEF and CEPR. Contact information: Department of Economics, Università di Napoli Federico II, Via Cintia, 80126 Naples, Italy, ph. +39-081-675306, e-mail: mrpagano@tin.it.

${ }^{\S}$ Universität Mannheim and CEPR. Contact information: Department of Economics, Universität Mannheim, L 7,3-5, 68131 Mannheim, Germany, tel. +49-621-181 1916, email: vthadden@pool.uni-mannheim.de. 


\section{Introduction}

What determines the yield differentials between bonds? Even though research has shown that the moments of bonds' return distribution and liquidity typically both play a role, we still understand imperfectly the relative importance of these two determinants and their possible interactions.

The European Monetary Union (EMU) offers a particularly good arena to examine these issues and sharpen our understanding, because in the euro area we can observe bonds issued by several sovereign issuers, without the complications arising from different currencies and different bond conventions, but with variation in liquidity. Even though since EMU's inception in 1999 yields on euro-area government bonds converged significantly, these bonds are still not regarded as perfect substitutes by market participants: non-negligible differences in yields across countries have remained, to different extents for different issuers and maturities, and they fluctuate over time. Even the bonds issued by AAA-rated issuers are not regarded as perfect substitutes, so that for example French bonds traded in the cash market are not seen as a perfect hedge for positions in Bund futures. ${ }^{1}$

A possible reason for these persistent differentials is persistent risk differences. Different sovereign issuers are perceived as having different solvency risks, in spite of the provisions of the Stability Pact. A second possible explanation is liquidity. This is indeed the explanation that is often advanced by practitioners.

However, a look at the time-series behavior of Euro-area yield differentials suggests that neither one of these two factors in isolation is likely to provide the full answer. First, as shown below, the yield differentials relative to the German Bund tend to fluctuate together, much more than measures of liquidity, such as bid-ask spreads, do. This suggests that liquidity alone cannot be the full answer, and that there must be other factors driving the differentials' time-series behavior. Such factors are likely to be related to international investment opportunities or global risk perceptions. For instance, even if the default risk of the Italian and French governments relative to the German one were very stable over time, a changing world price for risk could induce the implied yield differentials to fluctuate together. But this cannot be the full story either. Sizable yield differentials have been observed for sev-

\footnotetext{
${ }^{1}$ See Pagano and von Thadden (2004) for an account of the integration of European bond markets and for a survey of the relevant literature.
} 
eral years even within the group of AAA-rated euro-zone countries: as late as 2002, 10-year AAA-rated Finnish debt yielded on average 20 basis points more than the 10-year German Bund. This suggests that indeed liquidity differences may play a role, as practitioners claim. ${ }^{2}$

To analyze these issues, we develop a simple asset-pricing model with exogenous transactions costs and endogenous liquidity demand. The model is kept deliberately simple in order to isolate the implications of our key assumption of endogenous liquidity demand. The most important insight of our theoretical analysis is that liquidity matters for pricing, but that it interacts with aggregate factors in a way that is different from what traditional CAPM-like asset pricing models would predict.

Our model is based on the idea that the demand for liquidity responds both to the magnitude of trading costs and to the availability of outside investment opportunities. First, investors are less inclined to trade securities with larger trading costs. Second, they are less likely to liquidate securities when outside investment opportunities are less attractive, a situation which is assumed to coincide with increased aggregate risk. As a result, when risk is expected to increase, investors' demand for liquidity abates, and the premium they place on more liquid securities declines. Therefore, although in general investors value liquidity, they value it less when risk increases.

A key ingredient of our model is the insight of Merton's (1971) Intertemporal CAPM that future investment opportunities matter for individual portfolio choice. In our model, when they choose their portfolio, investors know that they may want to rebalance it later, when they receive new information about their exposure to an aggregate factor. Since an increase in aggregate risk worsens the risk-return profile of non-marketable investments (such as private equity, for which no price effect compensates for increased risk), at times of high aggregate risk investors are less likely to liquidate marketable as-

\footnotetext{
${ }^{2}$ For instance, the increase of yield differentials relative to the Bund rate in late 1999 was explained as follows: "after having tested the waters of Europe's smaller bond markets, institutional investors are deciding they've had enough ... declining liquidity in the smaller debt markets is boosting the premiums these countries are having to pay investors compared with the core euro-zone nations" (Wall Street Journal Europe, November 3, 1999). Market practitioners clearly attribute remaining yield differentials to liquidity premia, which are held to be larger in thinner markets, irrespective of their credit rating: "'Peripheral issuers in Europe are in trouble: They're paying a huge liquidity premium' says Steven Mayor, chief bond strategist at ING Barings in London. He says that their problem comes down to the fact that some still only represent $1 \%$ to $2 \%$ of the euro-zone issuance" (ibidem).
} 
sets in order to move into alternative investments. This asymmetry between marketable and non-marketable assets together with the I-CAPM insight that heterogenous future investment opportunities impact current prices imply the cross-effect that is specific to our theory. As in any sensible theory, yields increase in expected transactions costs. But investors in our model understand that these transactions costs will only be incurred when they rebalance their portfolio later on, and that the frequency of this re-balancing decreases in aggregate risk. Hence, the direct effect of transactions costs (illiquidity) on yields is positive, but this effect is decreasing in aggregate risk.

These ideas contrast with those embedded in the model by Vayanos (2004), where the demand for liquidity is not sensitive to trading costs and increases at times of high risk. In Vayanos' model, fund managers are subject to withdrawals due to mutual fund liquidations (or binding margin requirements).if their performance falls below a given threshold. Therefore they are more likely to liquidate at times of high volatility, and these forced sales are naturally effected through the cheapest channel, i.e. by using the most liquid assets. So increases in volatility induce a flight to liquidity and an increase in the liquidity premium. Hence, while anticipated transactions costs increase an asset's required yield, as in our setting, this effect is amplified by aggregate risk: the two models have the same prediction regarding the direct effect of transaction costs, but the opposite prediction with respect to the interaction term.

Our model also differs from the CAPM model of liquidity by Acharya and Pedersen (2004), who implicitly assume that the demand for liquidity is inelastic to the magnitude of trading costs and that it does not vary predictably with the fundamental risk of securities. In their model, equilibrium returns compensate investors for anticipated trading costs (as in our setting), but also for liquidity risk: unanticipated changes in liquidity are priced to the extent that they generate covariance risk (due to commonality in liquidity) or exacerbate fundamental covariance risk. But the premium that investors are willing to pay for anticipated trading costs does not depend on fundamental risk, in contrast to both our setting and that by Vayanos.

The empirical implication of our model is that, while both increases in risk and illiquidity should reduce asset prices and drive up their returns, their interaction should have the opposite sign - that is, it should increase asset prices and dampen the increase in their required return. An estimation that ignores the effect caused by the interaction of liquidity with aggregate risk is 
likely to underestimate the direct impact of liquidity (as well as that of risk) on prices. We bring these ideas to the data using two years of daily observations on yields and liquidity variables for Euro-area sovereign bonds at the 5 -year and 10-year maturities. The results show that a standard proxy for aggregate risk - the yield difference between U.S. fixed- interest on swaps and U.S. government bonds at the corresponding maturity - is the single most important explanatory variable for Euro-area yield differentials. Liquidity differentials - as proxied by the difference between the local and the relevant reference bid-ask spread - play a role only in a subset of countries. Whenever it appears with a statistically significant coefficient, the bid-ask spread impacts positively the corresponding yield relative to that of the benchmark, as any asset pricing model would predict. However, different from other models, its interaction with the aggregate risk factor is negative and precisely estimated. In other words, (i) illiquidity appears to command a premium, as in most of the literature following Amihud and Mendelson (1986), and (ii) the size of such premium is reduced by covariation between the cost of illiquidity and aggregate risk.

To get an idea of the economic magnitude of our estimated effects, consider the case of the 10-years yield differentials on German government bonds. In the sample that we consider, which covers daily observations in 2002 and 2003, yields differentials fluctuated in a range between minus eight and twenty-five basis points. Our proxy for aggregate risk instead fluctuated in a range between twenty-five and eighty basis points, while liquidity differentials fluctuated between minus four and six basis points. Our estimates show that in periods of high aggregate risk (where the U.S. swap-bond differential is higher than seventy basis points) the effect of liquidity on yield differentials is not significantly different from zero and fluctuations in yield differentials depend exclusively on the risk factor. But in periods of low aggregate risk (U.S. swap-bond differentials below thirty basis points) liquidity differentials have a positive and significant impact on yield differentials: on average, an increase of one basis point in liquidity differentials is associated with an increase of two basis points in yield differentials (which in these periods are below ten basis points). Similar qualitative results hold for the 5-year differentials on French government bonds, keeping in mind that these differentials are on average half the 10-year differentials, so that all measures of impact have to be reduced proportionately.

The structure of the paper is as follows. Section 2 relates the paper to the relevant literature. Section 3 presents the data and describes the stylized 
facts that emerge from them. Section 4 lays out the model and its predictions. Section 5 presents and discusses the estimation results. Section 6 concludes. In an appendix, we generalize the basic model used in the main text to include uncertainty and risk aversion. A short second appendix describes our data.

\section{Related Literature}

This paper adds to a considerable literature on the relation between returns and liquidity. At a theoretical level, two main views have been advanced to explain why liquidity should be priced by financial markets: illiquidity (i) creates trading costs, and (ii) can itself create additional risk. These views are not mutually exclusive, although they have emerged sequentially in the literature. This paper builds on the first view and develops it in a new direction, which is similar in spirit to that of the second view.

The "trading cost view" holds that illiquid securities must provide investors with a higher expected return to compensate them for their larger transaction costs, controlling for fundamental risk. The prediction here is a cross-sectional one: risk-adjusted expected return must be higher for less liquid securities. This view, first proposed and tested by Amihud and Mendelson (1986), has been the basis of a vast empirical literature. Many subsequent studies of stock-market data have confirmed a significant crosssectional association between liquidity (as measured by the tightness of the bid-ask spread or trading volume) and asset returns, controlling for risk: among these are Brennan and Subrahmanyam (1996), Chordia, Roll and Subrahmanyam (2000), and Datar, Naik and Radcliffe (1998).

Other studies have focussed on liquidity effects in fixed-income security markets. Here, too, the initiators were Amihud and Mendelson (1991), who showed that the yield to maturity of treasury notes with six months or less to maturity exceeds the yield to maturity on the more liquid treasury bills. Studies on U.S. public debt by, e.g., Warga (1992), Daves and Ehrhardt (1993), Kamara (1994) and Krishnamurthy (2002) confirmed these findings, although using more recent data Strebulaev (2003) found that the yield spread between bills and matched notes is much smaller than previously found, especially when bills are on-the-run. Goldreich, Hanke and Nath (2002) have refined this line of analysis by investigating the impact of expected liquidity on securities' prices. They analyze the prices of Treasury securities as their liquidity changes predictably, in the transition from on-the- 
run to the less liquid off-the-run status, and show that the liquidity premium depends on the expected future liquidity over their remaining lifetime rather than on their current liquidity.

The "liquidity risk view", developed in particular by Pastor and Stambaugh (2003), highlights that liquidity is priced not only because it creates trading costs, but also because it is itself a source of risk, since it changes unpredictably over time. Since investors care about returns net of trading costs, the variability of trading costs affects the risk of a security. In an important paper, Acharya and Pedersen (2004) show theoretically in a CAPM framework with overlapping generations of investors that liquidity risk should be priced to the extent that it is correlated across assets and with asset fundamentals, and uncover evidence consistent with this prediction. Similarly, Ellul and Pagano (2006) show that the initial underpricing of IPO shares should compensate investors also for the expected illiquidity and for the liquidity risk that investors face in after-market trading, and not only for fundamental risk and adverse selection problems. Also Gallmeyer, Hollifield and Seppi (2006) propose a model of liquidity risk where traders have asymmetric knowledge about future liquidity, so that less informed investors try to learn from the amount of current trading volume how much liquidity there may be in the future. They show that current liquidity is a predictor of future liquidity risk, and therefore is priced.

Our paper puts forward what may be labeled the "risk-liquidity interaction view": we point out that liquidity alters the impact of changes in risk on current prices and yields. So here the emphasis is not on liquidity risk (indeed in this approach future liquidity is perfectly anticipated), but rather on the interaction between liquidity and aggregate risk. In our model, changes in aggregate risk affect the liquidity premium that assets with lower transactions costs command. As noted in the introduction, this parallels the work by Vayanos (2004), who also uses constant exogenous transactions costs to model illiquidity. Our model has the same prediction as his regarding the direct effect of transaction costs, but the opposite prediction with respect to the interaction term, as explained in the previous section: in our setting higher aggregate risk makes investors less eager to trade away from the existing portfolio of marketable assets, and therefore reduces liquidity demand and liquidity premia, while Vayanos (2004) predicts that high volatility amplifies the effect of illiquidity and therefore increases liquidity premia. ${ }^{3}$

\footnotetext{
${ }^{3}$ It is useful to emphasize that this effect arises from the interaction of liquidity and the
} 
On the empirical front, our analysis adds to a growing recent literature on Euro-area yield differentials. Codogno, Favero and Missale (2003) estimate models of Euro-area differentials with both monthly and daily data. Their estimates based on monthly data show that for most countries only international risk factors, and not domestic ones, have explanatory power (the former being proxied by U.S. bond yield spreads and the latter by national debt/GDP ratios). In their estimates of daily data (that refer to 2002 only), macroeconomic variables are not included because they move too slowly to allow the estimation of the impact of the domestic risk factor. Again, the international factor is statistically significantly for most countries, while liquidity (as measured by trading volume) is significant only for France, Greece, the Netherlands and Spain.

Geyer, Kossmeyer and Pichler (2004) estimate with weekly data a multiissuer state-space version of the Cox-Ingersoll-Ross (1985) model of bond yield spreads (over Germany) for four EMU countries (Austria, Belgium, Italy, and Spain). They find that idiosyncratic country factors have almost no explanatory power, and yield-spread data reflect mainly a single ("global") factor, whose variation can, to a limited extent, be explained by EMU corporate bond risk (as measured by the spread of EMU corporate bonds over the Bund yield), but by nothing else - in particular not by measures of liquidity. Their measurement of liquidity variables is, however, at best indirect, as they do not use data on bid-ask spreads, but rather derived measures of liquidity, such as issue size and the yield differential between on-the-run and off-therun bonds. Despite the considerable differences in the methodology and data used, both, Geyer, Kossmeyer and Pichler (2004) and Codogno, Favero, and Missale (2003) agree on the finding that yield differentials under EMU are driven mainly by a common risk (default) factor, related to the spread of corporate debt over government debt, and suggest that liquidity differences have at best a minor role in the time-series behavior of yield spreads. As we shall see, our results, which rely on a more direct measure of liquidity (daily bid-ask spreads), confirm the former result, but also highlight that the effect of liquidity cannot be properly gauged without taking into account its interaction with changes in the common risk factor.

Beber, Brandt, and Kavajecz (2007) complement the MTS data on market prices and bid-ask spreads with daily data on credit default swaps for

common risk factor of government bonds. Concerning asset-specific risk, our model does not deliver more than the standard result that higher default risk increases the yield. 
European sovereign bonds to disentangle empirically the problems of flight to quality and of flight to liquidity. They show that credit risk and liquidity are positively correlated across European sovereign issuers and find, consistent with previous studies, that liquidity typically is of minor importance in explaining yields compared to credit quality. Yet, liquidity becomes an important determinant of yields in times of high market volatility, measured by a U.S. index (VIX) or by a European one (VSTOXX). This result contrasts with our evidence that the liquidity premium on Euro government debt tends to be lower when aggregate risk is higher. This difference in results may arise from the fact that Beber, Brandt, and Kavajecz (2006) control for countryspecific risk, but do not consider aggregate risk factors. ${ }^{4}$ In contrast, we model risk as being driven by a common factor, consistent with the results by Codogno, Favero, and Missale (2003) and Geyer, Kossmeyer, and Pichler $(2004) .5$

\section{$3 \quad$ Data and Stylized Facts}

The data that we use in the empirical analysis concern benchmark bonds' prices and liquidity indicators for the Euro area, observed at daily frequencies for the period from 1 January 2002 to 23 December 2003. The data are collected from the Euro MTS Group's European Benchmark Market trading platform, and refer to a snapshot taken at 11 a.m. (Central European Time) in all market days for the Telematico cash markets. The database contains: (i) the best five bid and ask prices across all markets, (ii) the aggregate quantity of all the outstanding proposals made at the best bid and best ask prices, and (iii) the daily trading volume of each bond on the EBM. From these data we calculate redemption yields, maturities and a range of liquidity-related variables described in the Appendix. We consider Austria, Belgium, Finland, France, Germany, Italy, the Netherlands, Portugal and Spain. We do not include Greece and Ireland in the sample, because in 2002 the convergence process to EMU was still ongoing for Greece, while the Euro MTS data for Ireland become available only at a very late stage of our sample.

\footnotetext{
${ }^{4}$ Other work has investigated the high-frequency impact of credit risk on corporate bond spreads: see Longstaff, Mithal, and Neis (2005) and Ericsson and Renault (2006).

${ }^{5}$ Another difference between the two studies lies in the data set, which refers to a largely non-overlapping different time period, and to a set of securities that is not identical.
} 
Table 1 provides descriptive statistics for the yield differentials relative to Germany (for 10-year bonds) and France (for 5-year bonds) and the bid-ask spreads by country. For 10-year benchmark bonds, average yield differentials range from 4.16 and 6.94 basis points for France and the Netherlands to 14.47 and 15.50 basis points for Italy and Portugal respectively, while the range of variation is smaller for 5 -year bonds. In both cases, the standard deviation indicates that yield differentials feature considerable time-series variability. The statistics reported in the lower panel indicate that bid-ask spreads are all very tight and stable over time. For 10-year benchmark bonds, average bid-ask spreads range from 2.52 and 2.86 ticks for Italy and France to 4.60 and 4.87 for Austria and Finland, respectively. German Bunds are the third most liquid bonds after Italian and French ones in the cash market, with a spread of 3.25 ticks. The situation is similar for 5 -year bonds.

Figure 1 illustrates the time variation of 10 year yield differentials between each country in our sample and Germany, taken as the reference country. For clarity, we report separately the data for the Netherlands, France and Austria in the upper panel, and for all the remaining countries in the lower panel of the Figure. Yield differentials have a clear tendency to comove. The presence of comovement is confirmed by Table 2, which reports the correlation between yield differentials over the sample period and presents a principalcomponents analysis. Correlations are very high both within and between groups, and the principal-components analysis shows that the first principal component explains above 90 percent of the variance of the series. Liquidity indicators behave differently. Figure 2 shows the difference in bid-ask spreads observed for benchmark bonds relative to German ones, for the same groupings of countries as those used in Figure 1. The figure reports five-days moving averages of the daily observations to smooth volatility. Clearly, liquidity indicators have a different time pattern from yield differentials. This is confirmed by the correlations and principal-components analysis shown in Table 2. The correlation between differentials in liquidity indicators is much lower than that between yields differentials. Moreover, the principal- components analysis reveals that for liquidity indicators at least six components are needed to explain the same proportion of the total variance as that explained by the first component in the case of yield differentials.

The principal-components analysis of Table 2 shows clearly that there is a common international factor in yield differentials in Europe. In Figure 3 we display the behavior of a variable that is often proposed in the literature as a proxy for this factor: the spread between the yield on 10-year fixed 
interest rates on swaps and the yield on 10-year U.S. government bonds. There is ample evidence of a common trend in international bond spreads (see, for example, Dungey et al.1997). The empirical literature on sovereign bond spreads in emerging markets shows that the yield of U.S. government bonds, the slope of the U.S. yield curve and risk indicators on the U.S. bond markets, are the main determinants of sovereign spreads (see, for example, Eichengreen and Mody, 2000; Barnes and Cline, 1997, and Kamin and Von Kleist, 1999, Arora and Cerisola, 2001). Blanco (2001) and Codogno et al. (2003) use proxies for global credit risk derived from the U.S. yield curve in their models of euro-zone government security yields. Consistent with these findings and with the results of Geyer, Kossmeier and Pichler (2004), Figure 3 shows that this international risk factor is strongly correlated with the first principal component of yield differentials in the Euro area.

\section{Theoretical Framework}

We consider a partial-equilibrium model with three dates $t=0,1,2$. There are two traded bonds, denoted by $A$ and $B$, and a riskless asset that yields a net return of $r$ per period. Bond $i=A, B$ pays its face value $V$ with probability $q_{i}$ and 0 with probability $1-q_{i}$ at date 2 and nothing at date 1 . Without loss of generality we assume that $q_{B} \leq q_{A}$ and interpret bond $A$ as the benchmark. The repayment probabilities of the two bonds are driven by a common factor $\alpha$. When this factor increases, both bonds are less likely to repay: $d q_{i} / d \alpha \leq 0 .{ }^{6}$ The purchase price of bond $i$ at date 0 is $p_{0 i}$. The bonds can be re-traded at date 1 at a bid price of $\left(1-t_{i}\right) p_{1 i}$, and ask price of $p_{1 i}$, where $t_{i}$ is a proportional transactions cost.

A continuum of investors $h \in[0,1]$ are ready to invest at date 0 in order to consume at date 2 . Investors are risk neutral and maximize date- 2 consumption. Investors may want to liquidate their bonds at date 1 to invest in alternative investment opportunities, which comprises non-marketable private equity and human capital. The expected return of these real investments is negatively affected by aggregate factor $\alpha$ :

$$
\bar{r}-e^{h} \alpha,
$$

\footnotetext{
${ }^{6}$ Note that since we work in a risk-neutral setting, there is no need to specify the variance-covariance structure of bond returns. We describe such an extension for the case of risk-averse investors in the appendix.
} 
where $\bar{r}>0$ is the maximal expected return and $e^{h} \in[0, e]$, is a personspecific parameter that captures investor $h$ 's exposure to the aggregate factor. In our risk-neutral setting, the aggregate factor can be anything that depresses the profitability of real investment opportunities as well as reducing the solvency of marketable debt, such as the likelihood or severity of macroeconomic downturns. Accordingly, the individual factor $e^{h}$ can be thought as the sensitivity of a person's private investment opportunities to this common factor, as determined for instance by the sector of her family firm. In a model with risk-averse investors and risky investments, the common factor $\alpha$ would instead capture aggregate risk, while the individual factor $e^{h}$ would measure the investor's exposure to it. We sketch such an extension of the model in the appendix.

The assumption that the common factor $\alpha$ affects both the returns to marketable assets (in our case, the occurrence of default) and those to nonmarketable investments accords with a substantial body of evidence that finds a strong positive correlation between them, starting with the seminal paper on private equity returns by Moskowitz and Vissing-Jorgensen (2002). In our empirical analysis, we will proxy the factor $\alpha$ by the difference between the U.S. corporate swap rate and the treasury yield, a measure typically used to describe aggregate corporate risk (although it also captures other macroeconomic factors).

As the investor's exposure to the aggregate factor, $e^{h}$, increases over its support, the expected return of $h$ 's investment opportunity falls. We assume that $e^{h}$ satisfies the law of large numbers, so that uncertainty washes out in the aggregate and individual probabilities are the same as aggregate frequencies. Let us denote by $G$ the differentiable cumulative distribution function of $e^{h}$ and by $g=G^{\prime}$ its density function.

At date 1, an investor will liquidate his holdings of bond $i$ to invest in his outside investment opportunity if and only if the latter's expected return exceeds the expected return of the bond over its residual life, net of transactions costs:

$$
\bar{r}-e^{h} \alpha>\frac{q_{i} V}{\left(1-t_{i}\right) p_{1 i}} .
$$


Hence, investor $h$ will sell his holdings of bond $i$ with ex-ante probability

$$
\begin{aligned}
\pi_{i} & =\operatorname{prob}\left(e^{h}<\frac{\bar{r}}{\alpha}-\frac{q_{i} V}{\alpha\left(1-t_{i}\right) p_{1 i}}\right) \\
& =G\left(\frac{\bar{r}}{\alpha}-\frac{q_{i} V}{\alpha\left(1-t_{i}\right) p_{1 i}}\right) .
\end{aligned}
$$

Note that here investors liquidate their assets as a function of changing investment opportunities, and therefore as a function of market prices and yields. In other words, in this model demand for liquidity is price-elastic.

At the interim date, investors will buy bond $i$ only if (1) does not hold and if the bond does not yield less than the safe investment, i.e. if its price is sufficiently low:

$$
p_{1 i} \leq \frac{q_{i} V}{1+r} \equiv v_{i}
$$

Hence, $p_{1 i}=v_{i}$ is the maximum possible price for an equilibrium at date 1 to exist. Necessary for the existence of an equilibrium is therefore that aggregate demand for liquidity at this price is positive, i.e. that $\bar{r}$ is sufficiently large. If $\bar{r}$ were too small, even the investors with the most profitable investment opportunity would value them less than their bond holdings and no investor would ever want to sell bonds at date 1 .

No-arbitrage implies that the expected yields of all assets are equalized in equilibrium. Hence (4) must hold with equality, ${ }^{7}$ implying:

$$
\begin{aligned}
p_{1 i} & =v_{i}, i=A, B \\
\pi_{i} & =G\left(\frac{\bar{r}}{\alpha}-\frac{1+r}{\alpha\left(1-t_{i}\right)}\right) .
\end{aligned}
$$

In particular, the discount rate between dates 1 and 2 is $r$, the same as between 0 and 1 . The expected payoff of bond $i$ at date 0 therefore is

$$
p_{0 i}=\pi_{i} \frac{\left(1-t_{i}\right) p_{1 i}}{1+r}+\left(1-\pi_{i}\right) \frac{q_{i} V}{(1+r)^{2}}=\frac{\left(1-\pi_{i} t_{i}\right) q_{i} V}{(1+r)^{2}},
$$

because investors have rational expectations over their future decision to either sell (which occurs with probability $\pi_{i}$ ) or hold on to the bond (which

\footnotetext{
${ }^{7}$ In a closed economy with no short-selling allowed there could be an equilibrium in which (4) holds with strict inequality. Clearly, this is of no interest in our setting.
} 
occurs with probability $1-\pi_{i}$ ). So the bond's pledged yield to maturity is

$$
1+Y_{i}=\frac{V}{p_{0 i}}=\frac{(1+r)^{2}}{\left(1-\pi_{i} t_{i}\right) q_{i}}
$$

The yield ratio between the two bonds is simpler to calculate than the yield differential. It is given by

$$
\frac{1+Y_{B}}{1+Y_{A}}=\frac{1-\pi_{A} t_{A}}{1-\pi_{B} t_{B}} \cdot \frac{q_{A}}{q_{B}}
$$

By using the approximation $\ln (1+x) \approx x$ the yield differential at date 0 can be approximated simply by:

$$
\Delta Y=Y_{B}-Y_{A} \approx \pi_{B} t_{B}-q_{B}-\pi_{A} t_{A}+q_{A} .
$$

This expression for the yield differential is intuitive. First, there is a direct positive impact of transactions costs. If $\pi_{i}$ were constant, that is, the probability of liquidation were not endogenously chosen by investors, then transaction costs would, as usual, drive up yields. Equivalently, greater bond liquidity would be associated with lower required yields. This is clear from (7): if $\pi_{i}$ is constant and the cost $t_{B}$ of trading bond $B$ increases, its yield increases relative to that of bond $A$. The reason is that the buyer of the asset anticipates trading costs that must be compensated. As these costs only materialize if the holder trades at date $1, t_{B}$ is weighed with the probability of this event, which is $\pi_{B}$.

The second feature of $(7)$ is that the yield differential increases in fundamental risk: the higher the risk of default of, say, bond $B$, which is $1-q_{B}$, the higher its required yield compared to bond $A$. Given the absence of risk aversion in our model, this is not a risk premium but simply reflects the reduction in the discounted expected payoff of the bond. The impact of fundamental risk and of liquidity costs on yield spreads in (7) is standard and in line, for example, with the empirical findings of Beber, Brandt, and Karavacz (2006) for Euro government bonds.

However, the response of bond yields to changes in liquidity and risk become more interesting once one takes into account that the probability of liquidation is endogenous in this model. This probability itself reacts to changes in both transaction costs (the terms at which the "supply of liquidity" is available) and outside investment opportunities (that determine 
the "demand for liquidity" by market participants). Indeed, as we shall see, it also depends non-trivially on the interaction between the two.

As one would expect, both higher transaction costs (higher $t_{i}$ ) and less attractive aggregate investment opportunities (higher $\alpha$ ) reduce a given bond's probability of liquidation $\left(\pi_{i}\right)$ :

$$
\begin{aligned}
\frac{\partial \pi_{i}}{\partial t_{i}} & =-\frac{1+r}{\alpha\left(1-t_{i}\right)^{2}} g\left(\frac{\bar{r}}{\alpha}-\frac{1+r}{\alpha\left(1-t_{i}\right)}\right)<0, \\
\frac{\partial \pi_{i}}{\partial \alpha} & =-\frac{1}{\alpha^{2}}\left(\bar{r}-\frac{1+r}{1-t_{i}}\right) g\left(\frac{\bar{r}}{\alpha}-\frac{1+r}{\alpha\left(1-t_{i}\right)}\right)<0 .
\end{aligned}
$$

Intuitively, if transactions costs increase, i.e. the bond becomes less liquid, then liquidating it becomes less attractive, hence the probability of selling decreases. Similarly, if the aggregate risk factor increases, the investors' market investment opportunities become less attractive, which again decreases their probability of selling the bond. ${ }^{8}$

Equipped with these results, we can now explore how risk and liquidity affect bond yields in our simple model. For simplicity, we perform the comparative statics of the yield differential (7) with respect to $t_{B}$ only (the effect of $t_{A}$ is analogous):

$$
\begin{aligned}
\frac{\partial \Delta Y}{\partial t_{B}} & =\pi_{B}+\frac{\partial \pi_{B}}{\partial t_{B}} t_{B} \\
\frac{\partial \Delta Y}{\partial \alpha} & =\frac{\partial \pi_{B}}{\partial \alpha} t_{B}-\frac{\partial \pi_{A}}{\partial \alpha} t_{A}+\frac{\partial\left(q_{B}-q_{A}\right)}{\partial \alpha}, \\
\frac{\partial^{2} \Delta Y}{\partial t_{B} \partial \alpha} & =\frac{\partial \pi_{B}}{\partial \alpha}+\frac{\partial^{2} \pi_{B}}{\partial t_{B} \partial \alpha} t_{B} .
\end{aligned}
$$

The first term in (10) is positive, the second negative. Hence, the sign is a priori ambiguous. This ambiguity reflects two opposing effects - a direct and an indirect one. The direct effect of higher transactions costs is to drive up the price by a factor $\pi_{B}$ : with exogenous liquidation probability, this would

\footnotetext{
${ }^{8}$ We do not report the joint effect of an increase in transaction costs and in aggregate risk, $\partial^{2} \pi_{i} / \partial t_{i} \partial \alpha$. In our model, this cross-derivative cannot be signed unambiguously, but is positive for several examples of distributions $G$, including the uniform distribution. If it is positive, an increase in transactions costs (i.e. a decrease in liquidity) reduces the absolute value of the impact of the aggregate factor on trading volume $\pi_{i}$, hence, there is a flight to liquidity. Yet, as we shall see, this term will be of second order in the derivation of the relevant derivatives for yield spreads and can be neglected in a first approximation.
} 
be the only effect, as observed above in discussing (7). But when liquidation is endogenously determined, this effect is at least partly counteracted by a reduction of the trading probability, as described in (8). As this probability decreases, the relative price of the bond increases, because liquidation costs are incurred less often. Hence, this effect is proportional to $t_{B}$. To the extent that empirically bid-ask spreads in the bond market are very small (see Table 1 ), we expect the latter effect to be small in absolute terms and the overall effect to be positive.

The impact of risk on yield differentials in (11) has first two terms of small size and opposite sign, so that one would expect its overall sign to depend mainly on the sign of the third term $\partial\left(q_{A}-q_{B}\right) / \partial \alpha$, which measures the impact of aggregate risk on the fundamental risk of the two bonds. Two possibilities exist in principle. First, the effect of aggregate risk is similar for both bonds, in which case the term is approximately zero. Alternatively, the riskier bond is more sensitive to aggregate risk than the safer one, in which case we have $\partial\left(q_{A}-q_{B}\right) / \partial \alpha>0$. In this case, we have the well-known "flight to quality": an increase in aggregate risk makes the safer bond more attractive than the riskier one and hence drives up the yield differential. This is the typical effect stressed by practitioners. Our empirical strategy is to let the data tell us the sign of the derivative. In the appendix, we show how the positive sign arises in a simple model of imperfect but constant correlation of bond returns.

Finally, the joint effect of changes in risk and in liquidity is again ambiguous, but has one dominant element. As seen above, while the direct effect of aggregate risk on the probability of liquidation - the first term in (12) is always negative, the second term is ambiguous. This second term is the product of the flight to liquidity in terms of order flow and the transactions cost $t_{B}$. Since $t_{B}$ is small, we expect the negative first term to dominate.

We summarize the previous discussion in the following testable predictions regarding the effects of risk and illiquidity on the yield differential, where, recalling that changes in $t_{B}$ are mirror images of those in $t_{A}$, we measure illiquidity by the transaction cost differential $\Delta t$ :

Hypothesis 1. The yield differential is insensitive to aggregate risk if aggregate risk affects bonds of different fundamental value identically. It is increasing in aggregate risk if the fundamentals of riskier bonds react more to aggregate risk than those of less risky ones: 


$$
\frac{\partial \Delta Y}{\partial \alpha} \geq 0
$$

Hypothesis 2. The yield differential between the two bonds depends positively on their transactions cost differential:

$$
\frac{\partial \Delta Y}{\partial \Delta t}>0
$$

Hypothesis 3. The positive effect of transactions costs on the yield differential is dampened by aggregate risk:

$$
\frac{\partial^{2} \Delta Y}{\partial \Delta t \partial \alpha}<0
$$

While the first two predictions are in line with those of other existing models of asset pricing and liquidity, the third prediction is specific to our model. If, for example, bond trades are driven by consumption or endowment shocks, as in the OLG model of Acharya and Pedersen (2004) or the theoretical liquidity literature building on Diamond-Dybvig (1983), then the $\pi_{i}$ would be constant and, from (7), yield differentials would only depend on liquidity and aggregate risk directly. The cross-effect identified in (15) would be zero in this case. If bond sales were triggered by changes in consumption opportunities or other "supply side" considerations as in the delegated-portfolio management model of Vayanos (2004), rather than from changes in the riskreturn profile of alternative investments, the $\pi_{i}$ would depend positively on $\alpha$ rather than negatively, as in our model, and the cross-effect (15) would be positive. Then aggregate risk would amplify rather than dampen liquidity effects.

\section{Empirical Evidence}

The empirical strategy used to test the predictions of Section 4 is based on the estimation of a simultaneous equation model for yield differentials in the Euro area at different maturities. 
We measure the aggregate risk factor by the spread between $j$-year fixed interest rates on U.S. swaps, $R_{S W U S, t}^{j}$, and the yield on $j$-year U.S. government bonds, $R_{U S, t}^{j}$. We opt for this measure because of its high correlation with all U.S.-based measures of risk and because of its availability at different maturities. In the next section we report estimates obtained using alternative measures of risk and show that our results are robust to the choice of risk measure. The robustness of our estimates to different proxies for risk is important, since the swap-treasury differential could arguably reflect the taking on and unwinding of carry trades in the market: these trades (which are generally trades with a U.S. dollar leg) may explain why factors based on U.S. interest rates become international risk factors. While in principle this argument does not make this differential less suitable as a proxy for aggregate risk in the Euro area, it raises the doubt that our proxy itself may be affected by liquidity. But our robustness analysis indicates that this is unlikely; the strong and positive comovements of all the measures of risk at different maturities make it difficult to interpret them as affected by carry trades, which should have different effects on prices at different maturities. As for the liquidity factor, we considered a range of alternative liquidity indicators and select the bid-ask spread as the most significant measure.

In taking the model to the data, we take the following specification strategy. First, we choose German bonds as benchmarks for the ten-year maturity and French bonds for the five-year maturity. This choice is supported by the econometric evidence provided by Dunne, Moore and Portes (2002) and by the fact that traders commonly regard the 10-year Bunds as the 10-year Euro-area benchmark and French OATs as the 5-year Euro-area benchmark, because French bonds are seen as particularly liquid for the 5-year maturity bucket.

Second, as yield spreads in the euro area are very persistent and our predictions are derived within a static framework, we posit the following dynamic partial adjustment model for yield differentials:

$$
Y_{i, t}-Y_{b, t}=\rho_{i}\left(Y_{i, t-1}-Y_{b, t-1}\right)+\left(1-\rho_{i}\right)\left(Y_{i, t}-Y_{b, t}\right)^{*}+u_{i, t},
$$

where $u_{i, t}$ are independently identically distributed shocks and $\left(Y_{i, t}-Y_{b, t}\right)^{*}$ is the theory-consistent long-run equilibrium value for yield differentials. Third, we augment the specification with the differentials in the residual maturity of the benchmark bonds in country $i$ and the benchmark country, in order to filter out of the data the effect introduced by the different maturity of bench- 
mark bonds and the effect of changes in benchmarks occurring at different dates for different countries in the sample period. ${ }^{9}$

\subsection{The Baseline Model}

To sum up, we estimate as a baseline model the following eight-equation model, where the dependent variables are the yield differentials relative to a benchmark government bond for the other eight countries listed in Section 3 :

$$
\begin{aligned}
Y_{i, t}^{j}-Y_{b, t}^{j}= & \rho_{i}\left(Y_{i, t-1}^{j}-Y_{b, t-1}^{j}\right)+\left(1-\rho_{i}\right)\left(Y_{i, t}^{j}-Y_{b, t}^{j}\right)^{*}+ \\
& +\delta_{i}\left(M_{i, t}^{j}-M_{b, t}^{j}\right)+u_{i, t}, \\
\left(Y_{i, t}^{j}-Y_{b, t}^{j}\right)^{*}= & \beta_{1, i}\left(c_{i, t}^{j}-c_{b, t}^{j}\right)+\beta_{2, i}\left(R_{S W U S, t}^{j}-R_{U S, t}^{j}\right) \\
& -\beta_{3, i}\left(c_{i, t}^{j}-c_{b, t}^{j}\right)\left(R_{S W U S, t}^{j}-R_{U S, t}^{j}\right),
\end{aligned}
$$

where $\left(Y_{i, t}^{j}-Y_{b, t}^{j}\right)^{*}$ is the long-run equilibrium yield differential consistent with the theory, $M_{i, t}^{j}-M_{b, t}^{j}$ are differentials in the residual maturity of the benchmark bonds in country $i$ and the benchmark country, $R_{S W U S, t}^{j}-R_{U S, t}^{j}$ is the spread between $j$-year fixed interest rates on U.S. swaps, $R_{S W U S, t}^{j}$, and the yield on $j$-year U.S. government bonds, $R_{U S, t}^{j}$, and $c_{i, t}^{j}-c_{b, t}^{j}$ is the differential between the bid-ask spread of bonds in country $i$ and the bidask spread of bonds in the benchmark country. The index $i$ varies across countries and the index $j$ varies across maturities (five and ten years). The estimation is performed by Seemingly Unrelated Regression (SUR), and the empirical results are shown in Tables 4.1 and 4.2.

The estimates for the 10-year maturity yield differential are presented in Table 4.1. The coefficient of the lagged dependent variable is always significant and close to unity, which indicates strong persistence of yield differentials. Also the coefficient of the maturity differential variable is uniformly

\footnotetext{
${ }^{9}$ We also tried different methods of dealing with these problems such as omitting from the sample dates in which benchmarks are changed or constructing constant maturity yields. We favour the use of the maturity differentials in that it is a natural way of correcting the differentials and it allows our liquidity indicator to operate during episodes in which liquidity might highly matter, such as at dates when benchmarks are changed.

An alternative to the maturity differential is the duration differential. However, the difference between these two measures is not very relevant in our case given that they both act as dummies to model the same jump in duration and maturity occurring in occasion of benchmark changes.
} 
positive and significant, confirming the importance of this correction. The corresponding results for the 5-year maturity are shown in Table 4.2. Again, the coefficient of the lagged dependent variable is positive and significant, but it is smaller for all eight countries, indicating lower persistence in the time-series behavior of 5 -year yield differentials. Also the maturity correction coefficient stays positive and significant for all eight countries.

More importantly, the coefficient of the aggregate risk factor is positive and significantly different from zero for all eight countries in both maturities, in accordance with Hypothesis 1 of Section 4. It ranges between 0.3 and 0.6. for the 10-year bonds and between 0.23 and 0.68 for the 5 -year bonds (except in the latter case for Germany, where the coefficient is virtually zero). Interpreting these positive coefficients from the perspective of the theory summarized in Hypothesis 1 leads us to conclude that the fundamental risk of non-benchmark bonds is perceived to be more strongly affected by changes in aggregate risk than that of benchmark bonds. So, higher aggregate risk - as proxied by our U.S. swap yield differential - is correlated with wider Euro-area yield differentials relative to the Bund (or respectively the OAT).

Turning to the liquidity variable, we note that at the 5-year maturity the coefficients of the liquidity variables are positive and significant in the case of Austria, Belgium, Spain, Italy, Netherlands and Portugal, in line with Hypothesis 2 of Section 4.

Finally, in line with Hypothesis 3, the interaction between liquidity and the aggregate risk factor has always a negative impact on the yield differentials. This finding is substantially confirmed at the 10-year maturity, although the results are weakened in the case of Spain and Italy. This evidence illustrates the importance of non-linearities in the effect of liquidity indicators on yield differentials. Interestingly, the coefficient of the liquidity differential variable becomes significant only when the interaction between liquidity indicators and the aggregate risk factor is also included in the regression. If the coefficient of the interaction is constrained to zero, then also the level of the liquidity indicator becomes insignificant.

This evidence does not simply reflect the fact that for less liquid bonds prices take more time to absorb the change in risks. In fact, we control for different dynamic effects across countries of the variables included in our model by having potentially different coefficients on the lagged dependent variable. Moreover a simple check, effected by adding further lags of the included variables, delivers non-significant parameters for higher order dynamics.

It could be observed that our SUR estimation is inefficient when valid 
cross-equation restrictions can be imposed on our model. This argument is strengthened in the context of our theoretical model where the cross-equation restrictions on the coefficients on the measure of liquidity and on the interaction between the aggregate risk factor and this measure are indeed implied by theory.

In Table 5, we explore this possibility by imposing cross-equation restrictions on our estimated models for 5-year and 10-year differentials. We test for the validity of cross-equation restrictions on each coefficient separately and on the full set of coefficients. Interestingly, the Wald statistics reported in Table 5 illustrate that the panel restrictions can only be validly imposed on the liquidity indicators at the 10-year maturity. When these restrictions are imposed, the effect of the liquidity variables is significant and in line with the prediction of the theory. Yet, this result does not carry over to the 5-year maturity, where the panel restrictions cannot be imposed on the liquidity variables. Furthermore, the panel restrictions on the coefficient of the aggregate risk factor are always rejected, in line with the predictions of the model where the impact of international risk on fundamental risk is heterogenous across different bonds.

Summing up, our empirical results are generally supportive of the implications of our theoretical framework: in particular, the aggregate risk factor always has a positive and significant effect on yields, and there is an important negative interaction between liquidity and the international factor.

\subsection{Robustness}

Swap spreads can be considered a good measure of risk, for a number of reasons. First, they are effectively the difference between the yields to maturity of two bonds with the same maturity. By no arbitrage, long-term yields to maturity can be exactly decomposed in a component reflecting the discounted sum of future one-period bond yields and in a component reflecting term premia. Taking the difference between two yields of exactly the same maturity, we are left with a quantity that exclusively reflects term premia. ${ }^{10}$ Second, they are available at the different maturities relevant to our study, thus enabling us to account for a non-flat term structure of risk premia. Third, U.S. swap spreads provide a measure of risk that does not refer to the

\footnotetext{
${ }^{10}$ Note that spreads can still depend on the level of interest rates, but only to the extent that the level of interest rates is differently reflected in the term premia associated to the two bonds on which yield differentials are computed.
} 
European market, and therefore are much more likely to be an exogenous variable in the estimation of the parameters of interest than any measure based on European yields. Fourth, as a spread between homogenous types of bonds, they are a superior measure of risk compared to the spread between Treasury bonds and corporate bonds. ${ }^{11}$

However, it must be recognized that swap spreads are a special measure of risk, in that they include the counterparty risk of swap dealers, ${ }^{12}$ and occasionally might reflect factors that are not related to aggregate risk. A close examination of Figure 3 reveals that the positive and strong comovement between the first principal component of yield differentials in the Euro area and our measure of risk has a clear exception in late July 2003. At this date, swap spreads suddenly increased for reasons related to the hedging of mortgage-backed securities and hence little related to international factors. It is therefore important to assess the robustness of our results.

We provide the relevant evidence in Table 6 , where we report the results of re-estimating our model for the 10-year yields differentials on a shorter sample, which excludes the July 2003 episode. The table also reports the evidence obtained by augmenting the baseline regression with two alternative measures of risk. The first is the yield spread between BBB long-term corporate bonds and AAA long-term corporate bonds; the second is an indicator based on the European equity market: the implied volatility from options on the Eurostoxx 50. The results show that our estimates are robust both to the choice of the sample size and to the use of different measures of risk. In particular, the results on the shorter sample fully confirm the evidence from our full sample with some slight modification of the original point estimates. Augmentation of the model with alternative measures of risk shows that, although all alternative measures of risk are significant, their inclusion does not affect the significance of all variables included in the original model. Overall, the significance of risk factors is more robust than that of the liquidity factor and of the interaction term. We perform similar robustness checks for the 5-year differentials, but for brevity we do not report the corresponding results, which confirm those obtained for the 10-year spreads.

\footnotetext{
${ }^{11}$ Duffee (1998) notes that the spread between Treasury bonds and corporate bonds is a spread between callable bonds and a mixture of callable and non-callable bonds. Given that the response of callable and non-callable bonds to shocks in the level of the term structure is different, the government-corporate spread is sensitive to the level of the term structure.

${ }^{12}$ Although, in practice this effect is minimal: see, for example, Duffie and Huang (1996).
} 
In the case of the 5-year bonds we also re-estimate the model with the German Bund as a benchmark instead of the French OAT. This modification leads to much less precise estimates of all relevant parameters and to a set of results that are much less consistent with those obtained for the 10-year differentials. We take this as confirmatory evidence of the econometric analysis by Dunne, Moore and Portes (2002) that indicates the OAT as the preferred choice of benchmark for the 5-year maturity.

Having chosen a U.S.-based measure of aggregate risk, a final robustness check concerns the inclusion of the dollar-euro exchange rate as an independent source of risk: in all specifications, this variable is insignificant.

\section{Conclusions}

This paper explores the determinants of observed yield differentials between sovereign bonds. It does so by drawing on data for long-tern bond yields in the Euro area. Inspection of daily data for the early EMU period indicates that there is a strong comovement in yield differentials of benchmark bonds, and that their first principal components explains more than ninety per cent of the variance. This common trend appears highly correlated with measures of aggregate risk. In contrast, liquidity differentials - proxied, for example, by bid-ask spread differentials - feature sizeable heterogeneity and no common factor.

To generate testable predictions about the relation between yield differentials, fundamental risk, and liquidity, we develop a simple model of the interplay between aggregate risk and transactions costs. Our model has two key novel features. First, the demand for liquidity responds to the magnitude of transaction costs and to changes in investors' opportunity set (rather than being determined by exogenous liquidation needs). Specifically, investors value liquidity less when alternative investment opportunities become less attractive. Second, if the payoff of alternative investments covaries with that of marketable assets, being both driven by a common factor, the equilibrium value of liquidity tends to be lower in worse aggregate states, as determined by this common factor.

The model predicts that bond yield differentials should increase in both liquidity and aggregate risk, with a non-linear term that captures the effect on required bond returns due to the interaction between liquidity and the aggregate factor. We test these predictions on daily data for the Euro-area 
sovereign yield differentials in 2002 and 2003. The econometric results show that the aggregate risk factor is consistently priced, while liquidity differentials are priced only for a subset of nine country/maturity pairs (out of a total of sixteen), and that the interaction of liquidity differentials with the risk factor is always negative when significant, in line with the prediction of the model. Our findings are also consistent with those of recent papers that find that the effect of liquidity variables on bond returns is not economically important when considered in isolation. In fact, when the coefficient of the interaction term between aggregate risk and liquidity is constrained to be zero, liquidity becomes insignificant throughout our regressions.

Our data do not allow us to draw conclusions regarding the effect of cross-sectional differences in macroeconomic conditions or fiscal policies. For example, simple cross-country regressions show that on average over the sample period, (average) yield spreads are positively correlated with (average) government debt/GDP ratios, which in turn are negatively correlated with (average) bid-ask spreads. But, being based on nine data points only, these cross-sectional estimates have little reliability, and in our time-series analysis we do not have sufficient variation in macroeconomic variables (such as debt/GDP ratios) to draw conclusions about possible macroeconomic determinants of the variables that we observe.

The implications of our analysis for policy-makers and for portfolio managers are rather more subtle. From a policy-making standpoint, the empirical estimates highlight the importance of the aggregate risk factor in determining bond yield spreads, and thus underscore the importance of good macroeconomic fundamentals to minimize exposure to the aggregate risk factor. Instead, there seems to be little need for further action on the liquidity side, because bid-ask spreads are already rather uniform and very small across European bond markets, at least for benchmark bonds. Instead, the lesson for portfolio management is that liquidity can affect the risk sensitivity of the assets being held, and that this interaction depends on the covariance of illiquidity costs with aggregate risk. In this sense, the lesson of our model in spite of its simplicity - may be considerably more general than our specific application to Euro-area bond markets. 


\section{Appendix 1: Extension to Risky Portfolios}

In this appendix, we sketch an extension of the model in which the investors' investment opportunities are risky and imperfectly correlated. As in the main text of the paper, the two bonds can either repay $\left(\widetilde{V}_{i}=V\right)$ or default $\left(\widetilde{V}_{i}=0\right)$. The probabilities are

$$
\left(\widetilde{V}_{A}, \widetilde{V}_{B}\right)=\left\{\begin{array}{cc}
(V, V) & \text { with probability } \gamma+\alpha, \\
(V, 0) & \text { with probability } p_{V 0}, \\
(0, V) & \text { with probability } 1-\alpha-\gamma-p_{V 0}, \\
(0,0) & \text { with probability } \alpha .
\end{array}\right.
$$

It is straightforward to show that the correlation between the two returns is

$$
\rho=\frac{\left(\alpha+\gamma+p_{V 0}\right)\left(p_{V 0}+\alpha\right)-p_{V 0}}{\sqrt{\left(\alpha+\gamma+p_{V 0}\right)\left(1-\alpha-\gamma-p_{V 0}\right)\left(p_{V 0}+\alpha\right)\left(1-p_{V 0}-\alpha\right)}} .
$$

Holding the correlation constant, for small values of $\alpha$ (which is the relevant case), an increase in $\alpha$ increases the variance of both bonds, hence $\alpha$ can be viewed as an indicator of aggregate risk. If we hold $\rho$ constant, this structure has two free parameters, namely the aggregate factor $\alpha$ and the relative attractiveness of bond $A$, which can be measured by $\gamma$.

The assumption $q_{A} \geq q_{B}$ (bond $A$ is the benchmark) implies that $\alpha+$ $\gamma+2 p_{V 0} \geq 1$. Under this assumption, for $\rho$ constant, it is straightforward (though tedious) to calculate that $\frac{\partial}{\partial \alpha}\left(q_{A}-q_{B}\right) \geq 0$ for small values of $\alpha$, as postulated in Section 4.

The alternative investment opportunity of investor $h$ pays off as follows:

$$
\widetilde{R}^{h}=\left\{\begin{array}{cl}
\bar{r}-\sqrt{e^{h}} & \text { with probability } \alpha \\
\bar{r} & \text { with probability } s \\
\bar{r}+\sqrt{e^{h}} & \text { with probability } \alpha
\end{array}\right.
$$

where $s>0, s+2 \alpha=1,0 \leq e^{h} \leq e$. For each $h$ we have $E \widetilde{R}^{h}=\bar{r}$ and $\operatorname{var}\left(\widetilde{R}^{h}\right)=2 \alpha e^{h}$. Hence, higher $\alpha$ means higher risk, and the investor bears more of the risk the greater her $e^{h}$. If she is risk-averse, she will therefore behave as if she maximized the certainty equivalent $\bar{r}-\alpha e^{h}$ considered in the main text.

If risk-averse, the investor's objective is to maximize $E u(c)$, where $u$ is increasing and concave,

$$
c=x_{A} \widetilde{V}_{A}+x_{B} \widetilde{V}_{B}+x_{C}(1+r)+x_{R} \widetilde{R}^{h}
$$


is final consumption, and the $x_{i}$ are the investor's end-of-period-1 holdings of the four assets.

Because of transactions costs, the first-order condition of this problem depends on whether the investor buys or sells in equilibrium. As an example, consider the case where the investor sells both bonds in order to invest alternatively. In this case, her first-order conditions are

$$
\begin{aligned}
E\left(\widetilde{V}_{A}-(1+r)\left(1-t_{A}\right) p_{1 A}\right) u^{\prime}(c) & =0, \\
E\left(\widetilde{V}_{B}-(1+r)\left(1-t_{B}\right) p_{1 B}\right) u^{\prime}(c) & =0, \\
E\left(\widetilde{R}^{h}-(1+r)\right) u^{\prime}(c) & =0 .
\end{aligned}
$$

Hence,

$$
\begin{aligned}
\left(1-t_{i}\right) p_{1 i} E\left[\widetilde{R}^{h} u^{\prime}(c)\right] & =E\left[\widetilde{V}_{i} u^{\prime}(c)\right], \quad i=A, B \\
\Leftrightarrow \quad \operatorname{cov}\left(\frac{\widetilde{V}_{i}}{p_{1 i}}-\left(1-t_{i}\right) \widetilde{R}^{h}, u^{\prime}(c)\right) & =\left(\frac{\bar{V}_{i}}{p_{1 i}}-\left(1-t_{i}\right) \bar{r}\right) E u^{\prime}(c)
\end{aligned}
$$

This condition on how the the excess return of each bond over the investor's (transactions costs adjusted) alternative return must covary with marginal utility is a standard CAPM-type condition, with the new feature that the alternative return is investor-specific. This "investor-specific $\beta$ " gives rise to a supply curve of bonds that is increasing in $p_{1 i}, i=A, B$, and decreasing in aggregate risk $\alpha$, as used in the main text. 


\section{Appendix 2: Data Description}

The data for 5-year and 10-year-maturity bonds from 1 January 2002 to 23 December 2003 are collected from Euro MTS Group's European Benchmark Market (EBM) trading platform, at 11 a.m. CET during all market days in the Telematico cash markets. The database contains the best bid or ask prices across all markets, the aggregate quantity of all of the outstanding proposals on basis of the best bid and best ask prices, and the daily trading volume of each bond on the EBM. From these data we calculate redemption yields, maturities and a set of time-varying liquidity variables for the benchmark bonds of each country in our sample. The countries are Austria, Belgium, Finland, France, Germany, Italy, the Netherlands, Portugal and Spain. We constructed the following liquidity variables (in all cases as the difference between the relevant country's value and the value observed for the benchmark, which was Germany for the 10-year bucket and France for the 5-year one):

- 5-day-moving-average of the bid-ask spread (in ticks);

- trading volume for the benchmark bond, in million of Euros;

- bid-side market depth, defined as the difference between bid and mid price, divided by the bid quantity;

- ask-side market depth, defined as the difference between mid price and ask price, divided by the ask quantity;

- maximum quantity available at the best 5 prices.

After experimentation, we selected the bid-ask spread as the most significant liquidity indicator, and reported the estimates of our non-linear empirical model only for this liquidity indicator. ${ }^{13}$

\footnotetext{
${ }^{13}$ This is confirmed for example by Beber, Brandt and Kavajecz (2006), who find no significant difference in the impacts of the four liquidity variables they construct from the MTS data base.
} 


\section{References}

[1] Acharya, Viral V., and Lasse Heje Pedersen. "Asset Pricing with Liquidity Risk." Journal of Financial Economics, 52 (2004).

[2] Admati, R. Anat, and Paul Pfleiderer. "A Theory of Intraday Patterns: Volume and Price Variability." Review of Financial Studies 1 (1988), $3-40$.

[3] Amihud, Yakov, and Haim Mendelson. "Asset Pricing and the Bid-Ask Spread." Journal of Financial Economics 17 (1986), 23-249.

[4] Amihud, Yakov, and Haim Mendelson. "Liquidity, Maturity, and the Yields on U.S. Treasury Securities." Journal of Finance 46 (1991), 14111425 .

[5] Arora, Vivek, and Martin Cerisola. "How Does U.S. Monetary Policy Influence Sovereign Spreads in Emerging Markets?" IMF-Staff-Papers 48 (2001), 474-98.

[6] Barnes, Kevin, and William Cline. "Spreads and Risks in Emerging Markets Lending." Institute of International Finance Working Paper No.97-1 (1997).

[7] Beber, Alessandro, Michael Brandt, and Ken Kavajecz. "Flight-toQuality or Flight-to-Liquidity? Evidence from the Euro-Area Bond Market." Review of Financial Studies, forthcoming (2007).

[8] Blanco Roberto. "The Euro-Area Government Securities Market. Recent Developments and Implications for Market Functioning." Banco de Espana, Servicio de Estudios Working Paper 0120 (2001).

[9] Brennan, Michael J., and Avanidhar Subrahmanyam. "Market Microstructure and Asset Pricing: On the Compensation for Illiquidity in Stock Returns." Journal of Financial Economics 41 (1996), 441-464.

[10] Chordia, Tarun, Richard Roll, and Avanidhar Subrahmanyam. "Market Liquidity and Trading Activity." Journal of Finance 56 (2000), 501-530.

[11] Codogno, Lorenzo, Carlo Favero, and Alessandro Missale. "Government Bond Spreads." Economic Policy 18 (2003), 503-532. 
[12] Datar, Vinay, Naik Narayan, and Robert Radcliff. "Liquidity and Stock Returns: An Alternative Test." Journal of Financial Intermediation 1 (1998), 203-219.

[13] Daves, Philip R., and Michael C. Erhardt. "Liquidity, Reconstitution, and the Value of U.S. Treasury Strips." Journal of Finance 48 (1993), 315-329.

[14] Diamond, Douglas W., and Dybvig, Philip H. "Bank Runs, Deposit Insurance, and Liquidity." Journal of Political Economy 91 (1983), 401419.

[15] Duffee Gregory. R., "The Relation between Treasury Yields and Corporate Bond Yield Spreads." Journal of Finance 53 (1998), 2225-2241

[16] Duffie Darrell and Ming Huang. "Swap Rates and Credit Quality." Journal of Finance 51 (1996), 921-950

[17] Dungey, Mardi, Vance L. Martin, and Adrian R. Pagan. "A Multivariate Latent Factor Decomposition of International Bond Yield Spreads." Journal of Applied Econometrics 15 (2000), 697-715.

[18] Dunne, Peter G., Michael J. Moore and Richard Portes. "Defining Benchmark Status: An Application Euro-Area Bonds." Discussion Paper 2002/10, CEPR DP 3490, NBER WP 9087 (2002). Revised version as 'Price Discovery in the European Bond Market', March 2006.

[19] Eichengreen, Barry, and Ashoka Mody. "What Explains Changing Spreads on Emerging Market Debt?" in Capital flows and the emerging economies: Theory, evidence, and controversies, S. Edwards ed., NBER Conference Report series, Chicago and London: University of Chicago Press (2000).

[20] Ellul, Andrew, and Marco Pagano. "IPO Underpricing and After-Market Liquidity." Review of Financial Studies 19 (2006), 381-421.

[21] Ericsson, Jan, and Olivier Renault. "Liquidity and Credit Risk." Journal of Finance 61 (2006), 2219-2250.

[22] Gallmeyer, Michael, Burton Hollifield and Duane Seppi. "Demand Discovery and Asset Pricing." Carnegie Mellon University Working Paper (2006). 
[23] Alois Geyer, Stephan Kossmeier and Stefan Pichler. "Measuring Systematic Risk in EMU Government Yield Spreads." Review of Finance 8 (2004), 171-197.

[24] Goldreich, David, Bernd Hanke, and Purnendu Nath. "The Price of Future Liquidity: Time-varying Liquidity in the U.S. Treasury Market." Review of Finance, 9 (2005), 1-32.

[25] Kamara, Avraham. "Liquidity, Taxes, and Short-Term Treasury Yields." Journal of Financial and Quantitative Analysis 29 (1994), 403417.

[26] Krishnamurthy, Arvind. "The Bond/Old-Bond Spread." Journal of Financial Economics 66 (2002), 463-506.

[27] Francis A. Longstaff, Sanjay Mithal, and Eric Neis. "Corporate Yield Spreads: Default Risk or Liquidity? New Evidence from the Credit Default Swap Market." Journal of Finance 55 (2005), 2213-2253.

[28] Moskowitz, Tobias J. and Annette Vissing-Jorgensen. "The Returns to Entrepreneurial Investment: A Private Equity Premium Puzzle?." American Economic Review 92 (2002), 745-778.

[29] Pagano, Marco, and Ernst-Ludwig von Thadden. "The European Bond Markets under EMU." Oxford Review of Economic Policy 20 (2004), 531-554.

[30] Pastor, Lubos, and Robert F. Stambaugh. "Liquidity Risk and Expected Stock Returns." Journal of Political Economy 111 (2003), 642-685.

[31] Strebulaev, Ilya. "Liquidity and Asset Pricing: Evidence from the U.S. Treasury Securities Market." Stanford University Working Paper (2003).

[32] Vayanos, Dimitri. "Flight to Quality, Flight to Liquidity, and the Pricing of Risk." NBER Working Paper No. 10327 (2004).

[33] Warga, Arthur. "Bond Return, Liquidity, and Missing Data." Journal of Financial and Quantitative Analysis 27 (1992), 605-617. 
TABLE 1

\section{Descriptive Statistics by Country}

Panel A. Euro-area yield differentials relative to Germany, 10 year maturity (resp. France, 5 year maturity), in basis points

\begin{tabular}{c|ccc|ccc}
\hline \hline & \multicolumn{2}{|c|}{ 10-year benchmark bonds } & \multicolumn{3}{|c}{ 5-year benchmark bonds } \\
\hline \hline Country & Mean & Median & St. dev. & Mean & Median & St. dev. \\
Austria & 10.05 & 9.46 & 7.19 & 3.35 & 0.74 & 9.22 \\
France & 4.16 & 5.62 & 4.36 & 3.57 & 2.37 & 4.70 \\
Netherlands & 6.94 & 6.92 & 4.48 & 6.07 & 5.60 & 6.87 \\
Belgium & 13.45 & 11.79 & 6.80 & 4.78 & 4.40 & 8.09 \\
Spain & 9.72 & 8.06 & 7.44 & -2.16 & -0.42 & 10.13 \\
Finland & 10.88 & 9.34 & 8.30 & 6.48 & 582 & 11.18 \\
Italy & 14.47 & 15.70 & 4.88 & 7.97 & 8.34 & 8.01 \\
Portugal & 15.50 & 14.48 & 7.73 & 6.46 & 12.03 & 16.76 \\
\hline \hline
\end{tabular}

Panel B. Bid-ask spreads in ticks

\begin{tabular}{c|ccc|ccc}
\hline \hline & \multicolumn{2}{|c|}{ 10-year benchmark bonds } & \multicolumn{3}{|c}{ 5-year benchmark bonds } \\
\hline \hline Country & Mean & Median & St. dev. & Mean & Median & St. dev. \\
Austria & 4.60 & 4.4 & 1.10 & 4.11 & 4.00 & 0.64 \\
France & 2.86 & 2.80 & 0.46 & 2.52 & 2.60 & 0.34 \\
Netherlands & 3.55 & 3.60 & 0.50 & 3.75 & 3.80 & 0.45 \\
Belgium & 3.47 & 3.40 & 0.53 & 2.71 & 2.60 & 0.31 \\
Spain & 3.47 & 3.20 & 0.80 & 2.94 & 2.60 & 0.78 \\
Finland & 4.87 & 4.60 & 1.09 & 4.07 & 3.80 & 0.81 \\
Italy & 2.52 & 2.40 & 1.37 & 2.12 & 2.00 & 0.43 \\
Portugal & 4.33 & 4.40 & 0.69 & 3.16 & 3.00 & 0.51 \\
Germany & 3.25 & 3.00 & 0.67 & 3.20 & 3.20 & 0.45 \\
\hline \hline
\end{tabular}


TABLE 2

Correlation and Principal Components of Euro-Area Yield Differentials, 10 Year Bonds, Relative to Germany

Panel A. Correlation matrix

\begin{tabular}{c|cccccccc}
\hline \hline Country & AT & FR & NL & BE & ES & FI & IT & PT \\
\hline Austria & 1 & - & - & - & - & - & - & - \\
France & 0.65 & 1 & - & - & - & - & - & - \\
Netherlands & 0.51 & 0.48 & 1 & - & - & - & - & - \\
Belgium & 0.88 & 0.72 & 0.61 & 1 & - & - & - & - \\
Spain & 0.88 & 0.67 & 0.58 & 0.94 & 1 & - & - & - \\
Finland & 0.84 & 0.81 & 0.73 & 0.93 & 0.90 & 1 & - & - \\
Italy & 0.75 & 0.84 & 0.52 & 0.82 & 0.80 & 0.89 & 1 & - \\
Portugal & 0.92 & 0.69 & 0.61 & 0.87 & 0.89 & 0.88 & 0.78 & 1 \\
\hline \hline
\end{tabular}

Panel B. Principal components

\begin{tabular}{c|cccccccc}
\hline \hline Component & 1 & 2 & 3 & 4 & 5 & 6 & 7 & 8 \\
\hline Eigenvalue & 7.28 & 0.26 & 0.16 & 0.13 & 0.06 & 0.05 & 0.03 & 0.01 \\
Proportion of variance & 0.91 & 0.03 & 0.02 & 0.016 & 0.008 & 0.006 & 0.004 & 0.001 \\
Cumulative proportion & 0.91 & 0.94 & 0.96 & 0.98 & 0.988 & 0.99 & 0.998 & 1 \\
\hline \hline
\end{tabular}


TABLE 3

Correlation and Principal Components of Euro-Area Bid-Ask Spread Differentials Relative to Germany

Panel A. Correlation matrix

\begin{tabular}{c|cccccccc}
\hline \hline Country & AT & FR & NL & BE & ES & FI & IT & PT \\
\hline Austria & 1.00 & - & - & - & - & - & - & - \\
France & 0.22 & 1.00 & - & - & - & - & - & - \\
Netherlands & 0.49 & 0.51 & 1.00 & - & - & - & - & - \\
Belgium & 0.39 & 0.46 & 0.44 & 1.00 & - & - & - & - \\
Spain & 0.58 & 0.26 & 0.60 & 0.35 & 1.00 & - & - & - \\
Finland & 0.48 & 0.21 & 0.54 & 0.26 & 0.76 & 1.00 & - & - \\
Italy & 0.09 & 0.37 & 0.19 & 0.26 & -0.08 & -0.11 & 1.00 & - \\
Portugal & 0.22 & 0.50 & 0.29 & 0.56 & 0.20 & 0.19 & 0.24 & 1.00 \\
\hline \hline
\end{tabular}

Panel B. Principal components

\begin{tabular}{c|cccccccc}
\hline \hline Component & 1 & 2 & 3 & 4 & 5 & 6 & 7 & 8 \\
\hline Eigenvalue & 3.46 & 1.76 & 0.80 & 0.61 & 0.48 & 0.38 & 0.29 & 0.19 \\
Proportion of variance & 0.43 & 0.22 & 0.10 & 0.08 & 0.06 & 0.05 & 0.04 & 0.03 \\
Cumulative proportion & 0.43 & 0.65 & 0.75 & 0.83 & 0.89 & 0.93 & 0.97 & 1 \\
\hline \hline
\end{tabular}


TABLE 4.1

Estimation of a System of Simultaneous Equations for Euro-Area 10-Year Yield Differentials

The equations are estimated by SURE, on a sample of daily observations from 1/1/2002 to 23/12/2003. The Panel shows the coefficient estimates for the 10-year maturity, spreads are on German bonds. Standard errors are reported within brackets below the coefficient estimates. An asterisk $\left(^{*}\right)$ and a cross $(\dagger)$ indicate that the corresponding coefficient is significantly different from zero at the 5 and 10 percent level, respectively.

\begin{tabular}{ccccccc}
\hline \hline Variable & Constant & Own lag & Maturity & Risk factor & B-A spread & Interaction \\
\hline Austria & $-0.167^{*}$ & $0.857^{*}$ & $0.280^{*}$ & $0.546^{*}$ & $0.043^{*}$ & $-0.077^{*}$ \\
& $(0.026)$ & $(0.016)$ & $(0.034)$ & $(0.060)$ & $(0.014)$ & $(0.026)$ \\
Belgium & $-0.129^{*}$ & $0.936^{*}$ & $0.357^{*}$ & $0.497^{*}$ & $0.052^{*}$ & $-0.099^{*}$ \\
& $(0.021)$ & $(0.007)$ & $(0.040)$ & $(0.043)$ & $(0.022)$ & $(0.048)$ \\
Spain & $-0.135^{*}$ & $0.867^{*}$ & $0.349^{*}$ & $0.485^{*}$ & 0.007 & -0.009 \\
& $(0.034)$ & $(0.018)$ & $(0.061)$ & $(0.077)$ & $(0.024)$ & $(0.047)$ \\
Finland & $-0.159^{*}$ & $0.956^{*}$ & $0.207^{*}$ & $0.467^{*}$ & -0.01 & -0.025 \\
& $(0.049)$ & $(0.006)$ & $(0.045)$ & $(0.118)$ & $(0.024)$ & $(0.079)$ \\
France & $-0.119^{*}$ & $0.945^{*}$ & $0.184^{*}$ & $0.321^{*}$ & 0.016 & -0.025 \\
& $(0.038)$ & $(0.01)$ & $(0.077)$ & $(0.072)$ & $(0.038)$ & $(0.079)$ \\
Italy & $-0.077^{*}$ & $0.912^{*}$ & $0.288^{*}$ & $0.290^{*}$ & 0.017 & -0.042 \\
& $(0.021)$ & $(0.01)$ & $(0.037)$ & $(0.047)$ & $(0.018)$ & $(0.043)$ \\
Netherlands & $-0.076^{*}$ & $0.891^{*}$ & $0.314^{*}$ & $0.305^{*}$ & $0.034^{*}$ & $-0.052^{\dagger}$ \\
& $(0.019)$ & $(0.012)$ & $(0.029)$ & $(0.042)$ & $(0.016)$ & $(0.032)$ \\
Portugal & $-0.150^{*}$ & $0.920^{*}$ & $0.384^{*}$ & $0.633^{*}$ & $0.080^{*}$ & $-0.139^{*}$ \\
& $(0.044)$ & $(0.010)$ & $(0.052)$ & $(0.099)$ & $(0.033)$ & $(0.07)$ \\
\hline \hline
\end{tabular}


TABLE 4.2

Estimation of a System of Simultaneous Equations for Euro-Area 5-Year Yield Differentials

The equations are estimated by SURE, on a sample of daily observations from $1 / 1 / 2002$ to $23 / 12 / 2003$. The Panel shows coefficients estimates results for the 5 -year maturity, spreads are on French Bonds. Standard errors are reported within brackets below the coefficient estimates. An asterisk (*) and a cross $(\dagger)$ indicate that the corresponding coefficient is significantly different from zero at the 5 and 10 percent level, respectively.

\begin{tabular}{ccccccc}
\hline \hline Variable & Constant & Own lag & Maturity & Risk factor & B-A spread & Interaction \\
\hline Austria & $-0.251^{*}$ & $0.833^{*}$ & $0.170^{*}$ & $0.679^{*}$ & $0.079^{*}$ & $-0.184^{*}$ \\
& $(0.039)$ & $(0.017)$ & $(0.011)$ & $(0.09)$ & $(0.023)$ & $(0.048)$ \\
Belgium & $-0.082^{*}$ & $0.774^{*}$ & $0.214^{*}$ & $0.297^{*}$ & -0.022 & -0.033 \\
& $(0.015)$ & $(0.016)$ & $(0.008)$ & $(0.034)$ & $(0.018)$ & $(0.042)$ \\
Spain & $-0.143^{*}$ & $0.693^{*}$ & $0.210^{*}$ & $0.337^{*}$ & $0.048^{*}$ & $-0.095^{*}$ \\
& $(0.013)$ & $(0.021)$ & $(0.007)$ & $(0.03)$ & $(0.020)$ & $(0.041)$ \\
Finland & $-0.106^{*}$ & $0.606^{*}$ & $0.205^{*}$ & $0.258^{*}$ & -0.018 & -0.025 \\
& $(0.017)$ & $(0.022)$ & $(0.005)$ & $(0.041)$ & $(0.012)$ & $(0.024)$ \\
Germany & -0.017 & $0.742^{*}$ & $0.168^{*}$ & 0.01 & -0.007 & 0.004 \\
& $(0.015)$ & $(0.018)$ & $(0.007)$ & $(0.03)$ & $(0.012)$ & $(0.026)$ \\
Italy & $-0.043^{*}$ & $0.584^{*}$ & $0.172^{*}$ & $0.231^{*}$ & $0.107^{*}$ & $-0.208^{*}$ \\
& $(0.016)$ & $(0.03)$ & $(0.006)$ & $(0.028)$ & $(0.017)$ & $(0.032)$ \\
Netherlands & $-0.123^{*}$ & $0.563^{*}$ & $0.191^{*}$ & $0.317^{*}$ & $0.017^{*}$ & $-0.045 *$ \\
& $(0.016)$ & $(0.021)$ & $(0.04)$ & $(0.036)$ & $(0.009)$ & $(0.020)$ \\
Portugal & $-0.122^{*}$ & $0.853^{*}$ & $0.240^{*}$ & $0.458^{*}$ & $0.052^{*}$ & $-0.125^{*}$ \\
& $(0.022)$ & $(0.010)$ & $(0.006)$ & $(0.05)$ & $(0.018)$ & $(0.04)$ \\
\hline \hline
\end{tabular}


TABLE 5

Testing Panel Restrictions

The table is based on a fixed-effects panel estimates for the 10-year and 5-year yield differentials. The p-value of the Wald test of the identity restriction of individual coefficients for all eight countries is shown on the right of the relevant coefficient. The p-value of the Wald test of the identity restriction of all the coefficients for all eight countries is shown in the bottom row. Standard errors are reported within brackets below the coefficient estimates. An asterisk $\left(^{*}\right)$ and a cross $(\dagger)$ indicate that the corresponding coefficient is significantly different from zero at the 5 and 10 percent level, respectively.

\begin{tabular}{ccccc}
\hline \hline & 10-year yield differentials & 5-year yield differentials \\
\hline \hline Variable & Coefficient and S.E. & Wald p-value & Coefficient and S.E. & Wald p-value \\
Own Lag & $0.956^{*}$ & 0.000 & $0.853^{*}$ & 0.000 \\
Maturity & $(0.006)$ & & $0.006)$ & 0.000 \\
Risk factor & $0.269^{*}$ & 0.000 & $0.232^{*}$ & 0.000 \\
(0.041) & $0.172^{*}$ & 0.000 & $0.372^{*}$ & 0.000 \\
Bid-ask spread & $(0.063)$ & & $(0.032)$ & $0.039^{*}$ \\
Interaction & $0.047^{*}$ & 0.207 & $(0.008)$ & 0.000 \\
Panel restriction & $(0.021)$ & & $-0.087^{*}$ & $(0.018)$ \\
\hline \hline
\end{tabular}


TABLE 6

Robustness Analysis

The table reports robustness analysis for the SURE system on 10-year yield differentials. We consider three alternative Risk Factors. R F 1 is the swap spread, R F 2 is the differential between yields on seasoned U.S. BAA bonds and seasoned U.S. AAA bonds (the source for these data is the FRED database), R F 3 is the implied volatility in options on the EUROstoxx 50. The source for these data is Datastream.

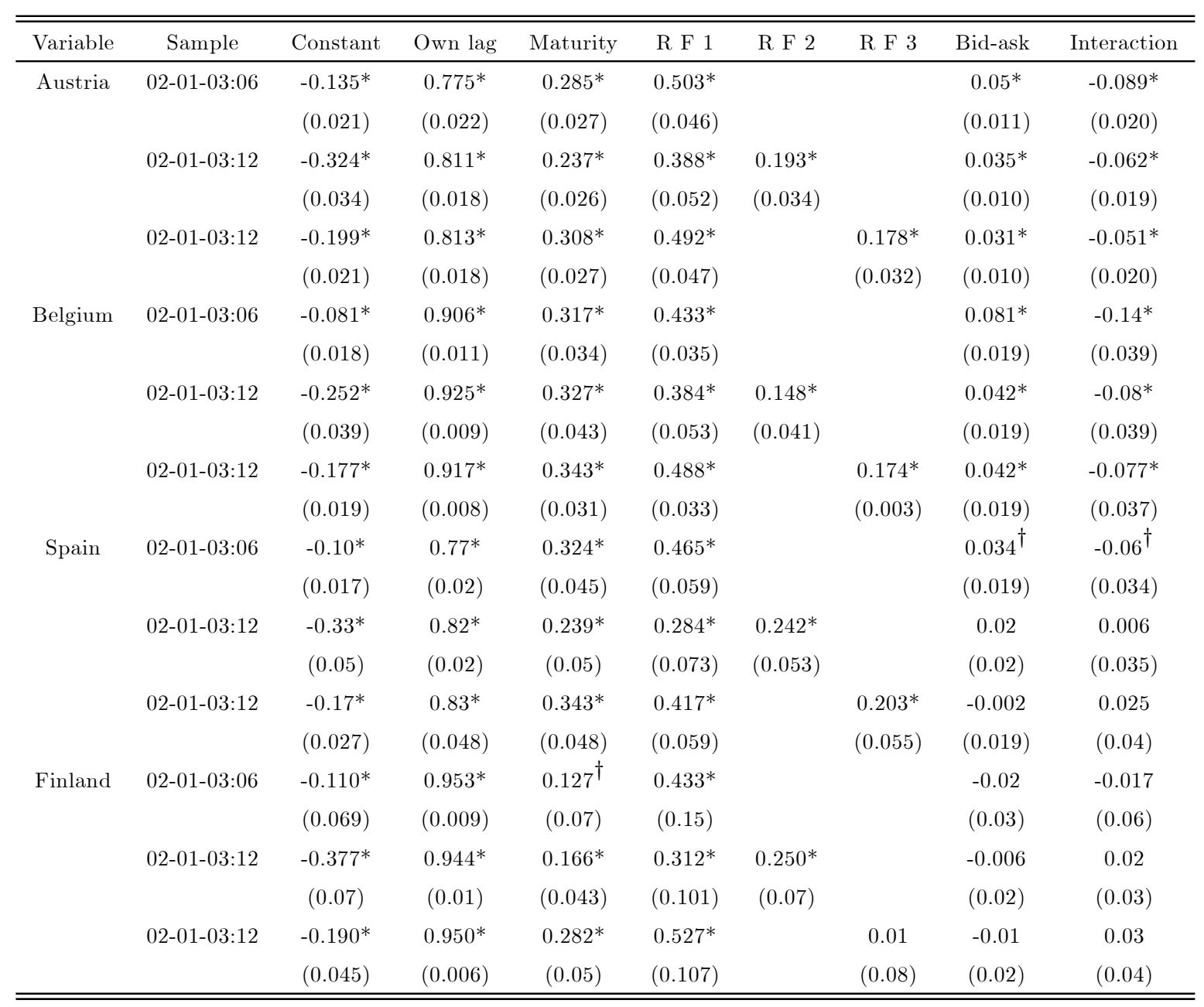


TABLE 6 (continued)

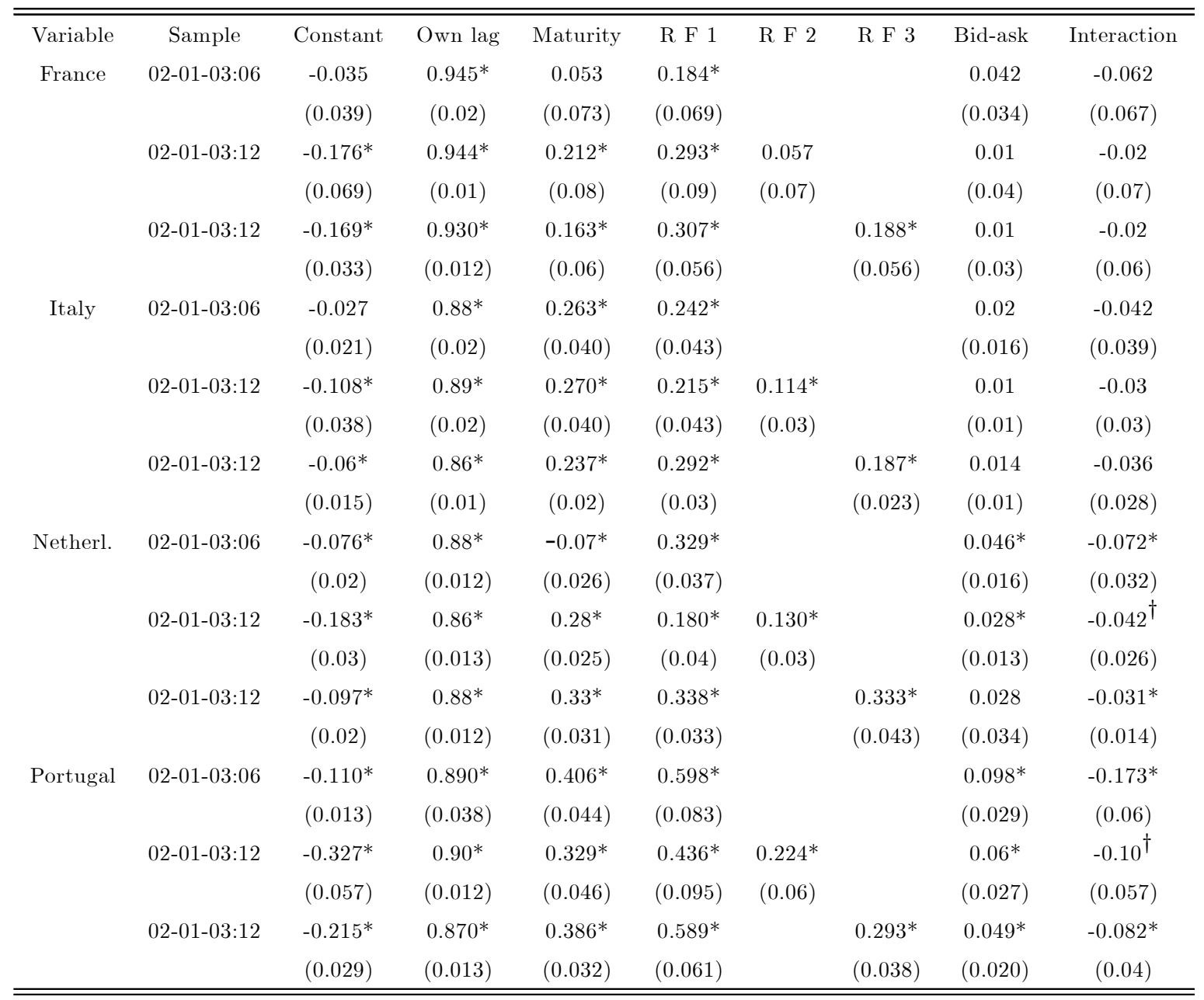


FIGURE 1

10-Year Yield Differentials in the Euro Area, Relative to German Bonds
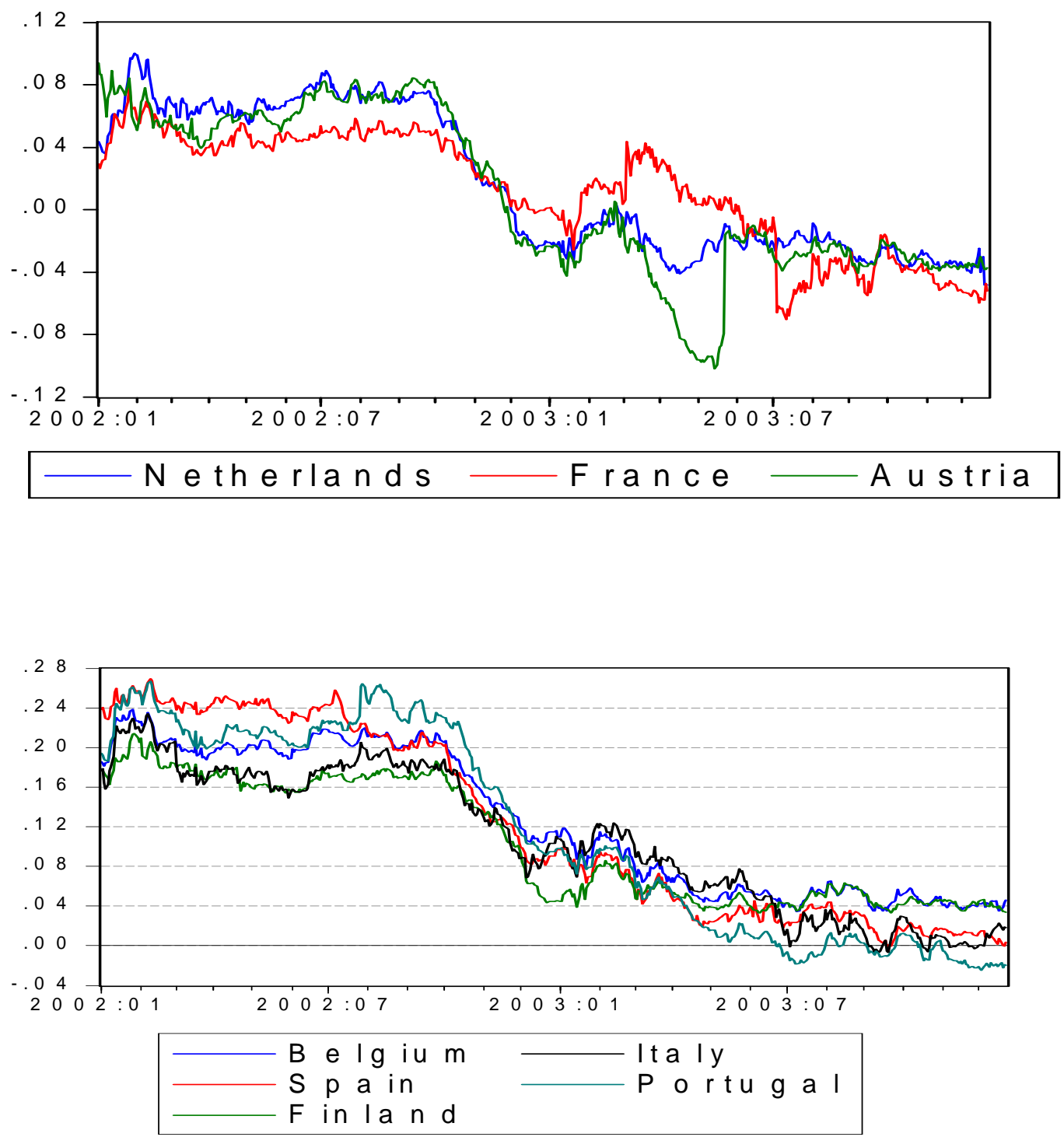
FIGURE 2

Bid-Ask Spread Differentials in the Euro Area, Relative to German Bonds

(10-year Benchmark Bonds, in Cents)
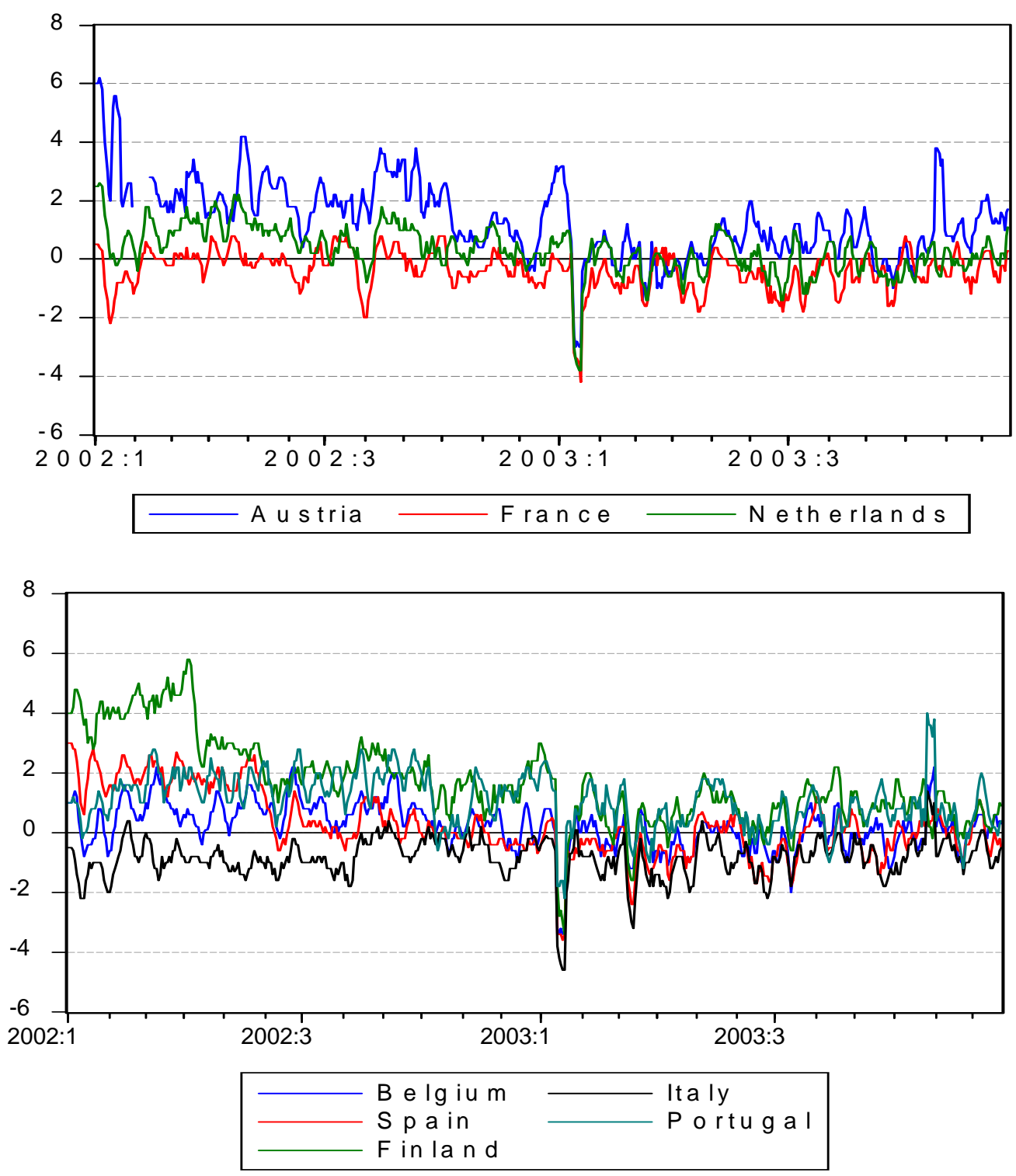
FIGURE 3

First Principal Components of Euro-Area Yield Differentials and the Spread Between the 10-Year Fixed Interest Rate on Swaps and U.S. Government Bond Yield

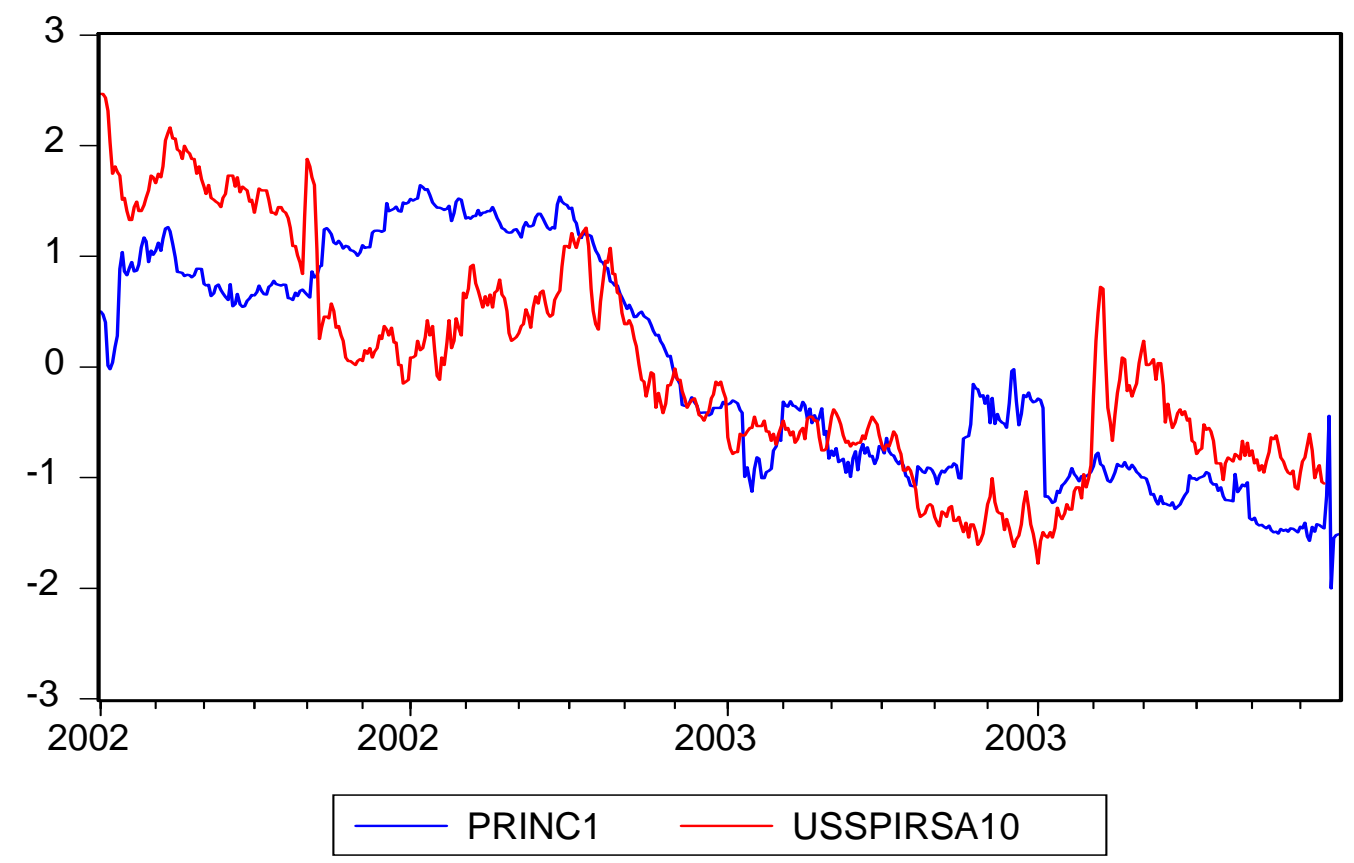

